\title{
A SOCIOLOGIA DO HOMEM EM SITUAÇÕES- LIMITE: redomas sensoriais, risco, performance e circo
}

por Roberto Moreira*

ALMEIDA, Luiz Guilherme Veiga de. Ritual, risco e arte circense: o homem em situações-limite. Brasília: Ed. da Universidade de Brasília, 2008. 314 p.

Imagine-se suspenso, de cabeça para baixo, a alguns bons metros do chão, balançando no ar e saltando na esperança de ser agarrado pelos braços do companheiro que está do outro lado. Porém, você não está se preparando para ser trapezista, mas para escrever uma tese de doutorado.

Há muitos modos de um cientista aproximar-se de seu objeto de pesquisa expondo seu próprio corpo a nenhum ou a um grande risco: observar microorganismos em um microscópio, ser alvo de elementos radioativos, embrenhar-se numa floresta, conviver com um povo desconhecido, inocular-se uma substância... Mas, sem dúvida, arriscar-se num picadeiro, sob a lona de um circo, deve ser algo único.

Pois foi isto que fez Luiz Guilherme Veiga de Almeida como trabalho de campo para escrever a tese de doutorado defendida no Departamento de Sociologia da Universidade de Brasília e agora publicada em livro pela editora da mesma Universidade, sob o título Ritual, risco e arte circense: o homem em situações-limite, no qual o autor se assina apenas Guilherme Veiga.

* Pesquisador Associado do Departamento de Sociologia da Universidade de Brasília. 
O objetivo era compreender as performances, manifestações que ele considera típicas do mundo contemporâneo, as quais, por sua vez, ajudam a compreender a sociedade que as gerou. Para isto, Guilherme Veiga matriculou-se como aluno da Escola Nacional de Circo (ENC), no Rio de Janeiro. Ele não chegou ao trapézio de vôo, como descrito no primeiro parágrafo, mas diversas outras modalidades circenses praticadas por Guilherme Veiga e primorosamente descritas ao longo do livro passam ao leitor a noção - melhor dizer a sensação -, das experiências vividas e a profunda adequação da escolha do objeto ao propósito da obra.

Porém, o inusitado do trabalho de campo está longe de ser o único mérito do livro. Em primeiro lugar chama a atenção a solidez da base histórica e teórica do autor, no que se refere ao teatro, às artes cênicas, ao espetáculo, à relação entre palco e platéia, à formação ocidental do modo de olhar a arte. Guilherme Veiga, além de artista, músico, compositor, fez mestrado em Filosofia na PUC do Rio de Janeiro, com uma dissertação sobre teatro e teoria na Grécia Antiga.

Essa consistente fundamentação na prática e na teoria surge nos dois primeiros capítulos, onde ele faz um denso mergulho na questão do olhar. Trata-se de uma questão central do pensamento sobre a arte no Ocidente: a separação entre o artista e o espectador, a concepção da arte como algo para ser visto, a divisão palco/platéia.

Guilherme Veiga retorna aos filósofos e ao teatro da antiga Grécia para demonstrar a gênese dessa noção de arte como espetáculo. Traz sua análise histórica até os meios de comunicação modernos, cinema, televisão, internet e suas tentativas de romper a barreira da quarta parede, criar a interação entre o espectador e o espetáculo. Finalmente chega à idéia de performance como uma espécie de espetáculo participativo. Vale notar a complexidade e as sutilezas do problema. $\mathrm{O}$ autor insere como questão central compreender como a 
atividade do espectador altera a natureza do que ele observa. Quando uma forma de expressão visa a um público, ela é um espetáculo; mas, há formas de expressão que não visam a um público e sim ao próprio praticante e, aqui, essa atividade ganharia o nome de ritual. $O$ ritual pode ter uma assistência, mas ele não se realiza para ela.

Questiona-se assim a hegemonia do olhar passivo na forma ocidental de pensar a arte que tem origem na concepção da expressão humana do ponto de vista do espectador. "Mas - diz o autor - quando se procura pensar eventos rituais, atividades de risco ou performances que ocorrem, por exemplo, de forma solitária, o pressuposto do espetáculo deixa de ser válido, pois tais performances nem sempre se explicam como atividades concebidas para serem vistas por uma platéia".

Guilherme Veiga tem a competência de mobilizar uma enorme quantidade de recursos (formação da noção de arte, especialmente do teatro, encontro da Europa com a América, grutas paleolíticas, o jogo, a guerra, os rituais, a caça, o cinema etc., além da pesquisa na Escola Nacional de Circo) a fim de sustentar uma proposta de conceitos (redoma sensorial - comunidades sensoriais - comunhão sensorial) para explicar certos fenômenos que seriam chamados de performance. Conjuga teóricos de antropologia, sociologia, história, filosofia e psicologia, valendo-se da teoria da arte, da história do teatro e da etimologia para questionar a noção de espetáculo e a cisão artista/espectador

De todo modo, a par de tantos méritos, a contribuição mais original é a criação do conceito de redoma sensorial. Para isso, ele parte da constatação de que o cotidiano de todos nós é multissensorial, já que envolve uma enorme quantidade de sons, sensações táteis, odores, visões, sabores, temperaturas, distâncias, cinestesia e sinestesia. O senso ou sentido comum é determinado então pelo horizonte da segurança sensorial ou pelo conjunto de 
sensações conhecidas e dominadas pela experiência de sua prática. A isto ele chama de redoma sensorial ordinária. No fundo, são coisas que fazemos automaticamente, sem precisar pensar, e que podem envolver simultaneamente dois ou mais sentidos, que interagem mas não produzem um efeito especial. Ele ressalva que nada impede que uma atividade cotidiana, como cozinhar, possa ser executada de modo extraordinário; entretanto, usualmente, ela não é desenvolvida com esse intuito.

Ele mostra também que elementos absolutamente triviais quando combinados de certa maneira ou transportados de seu ambiente de origem e inseridos em outro completamente diferente podem criar um efeito extraordinário e performático. A este processo ele chama de manipulação sensorial. De certo modo, é o mesmo mecanismo que se usa para obter o efeito ao contar uma piada ou o resultado intrigante dos desenhos de Escher.

O livro apresenta inúmeros exemplos interessantes da manipulação que, momentaneamente, confunde a percepção e os sentidos, produzindo um efeito sensorial extraordinário. O cinema, com sua aura de magia, foi e é ainda um campo fértil para a produção desses efeitos, desde realizações de seus primórdios (Guilherme Veiga lembra Voyage dans la lune, de Georges Méliès, Metropolis, de Fritz Lang, até 2001: uma odisséia no espaço, de Kubrick, Guerra nas estrelas, passando pelos documentários da cineasta Leni Riefenstahl na Olimpíadas de Berlim).

Também não se esquece de efeitos sensoriais extraordinários que podem ser obtidos quando se adentra lugares históricos excepcionais, como as ruínas de Pompéia, a cidade mexicana de Theotiucatán ou Ouro Preto. Basicamente altera-se a sensibilidade por deslocamentos no espaço ou no tempo.

$\mathrm{Na}$ parte dedicada à pesquisa na Escola Nacional de Circo, Guilherme Veiga se atém à idéia de redoma sensorial extraordinária. 
Além de se expor como aluno de circo, o autor dedicou-se a colher depoimentos, entrevistas, que lhe permitem formular idéias e mesmo tirar conclusões que aos olhos de um simples observador e até mesmo dos próprios entrevistados não seriam interpretadas com esta riqueza teórica.

Por exemplo, ele percebeu que para os acrobatas a redoma sensorial extraordinária é compreendida como um processo de aprendizagem e um evento limite. Os acrobatas sabem que seus sentidos estão todos voltados para o aprendizado daquela nova atividade até que ela seja dominada e passe a ser corriqueira e, portanto, as deixar de ser extraordinária, passa a ordinária. Só que o processo é infinito porque o acrobata busca sempre novos desafios, cada vez mais extraordinários.

Assim, surge a noção de risco que pode ser afastado iniciando-se o treinamento pelas atividades mais simples até chegar às mais complexas. É nesse processo de absorção de atividades extraordinárias e arriscadas que, diante de um público, por exemplo, o que para ele não passa de uma segunda natureza é visto como performance pelo observador externo. $\mathrm{O}$ mesmo se poderia dizer de um virtuose que, ao executar seu instrumento, "esconde" do público o imenso esforço feito durante anos para chegar àquela qualidade de execução.

Porém, diz o autor, é importante notar que, ao se submeter ao treino, o indivíduo se torna performático mesmo que jamais se apresente a um público; a origem da performance está no processo de transformação pela conquista de redomas sensoriais extraordinárias. A eventual apresentação a um público é apenas um evento secundário.

Ainda sobre a noção de risco, Guilherme Veiga ressalta que a palavra deve ser entendida em primeiro lugar como risco físico, envolvendo a possibilidade de lesões e, até mesmo, uma fatalidade. 
Mas, para efeito da análise, excluem-se as situações de risco que estejam fora do controle do indivíduo, como acidentes, efeito da poluição e outros. O risco físico analisado é aquele absolutamente necessário para a sobrevivência (exemplo da caça, em sociedades de caçadores) ou o que é assumido consciente e voluntariamente para a prática de certos rituais. Ele vai mais longe, mostrando como nas sociedades contemporâneas a questão do risco assume novas feições em virtude da ampliação da capacidade humana de conhecer os riscos (controle de doenças, acidentes de trabalho, etc.) e também pelo efeito paradoxal de que a mesma tecnologia que permite controlar melhor os riscos produz ela própria novos riscos. Nesse ponto, Guilherme Veiga percorre a relação de sociedades de diversas épocas com o risco (jogos, esportes, rituais, guerras) e menciona uma questão filosófica que sugere que os homens e a sociedade parecem não ter como objetivo obter uma sociedade isenta de riscos - não porque ela não possa ser realizada, mas porque não é desejada.

Isto o faz voltar ao circo como redoma sensorial extraordinária, dizendo que, em certo sentido, a acrobacia envolve destreza física (esporte), risco (guerra) e beleza (arte). Assim, o acrobata se aproxima do dançarino pela beleza, do esportista pela destreza física e, ainda, contém algo de guerreiro pela exposição ao risco. Claro que para cada uma dessas atividades altera-se a ordem de importância das habilidades.

O capítulo final do livro pode ser considerado o caderno de campo de um etnólogo e a primeira observação é que a própria tenda do circo é uma redoma sensorial isolada do que se passa do lado de fora e, no caso da Escola Nacional de Circo, um lugar particularmente conturbado da cidade, que é a Praça da Bandeira, na cidade do Rio de Janeiro. Em seguida, descreve as pessoas que freqüentam a Escola, cada uma das formas de acrobacias e malabarismos e as experiências sinestésicas a elas associadas. Por exemplo, as acrobacias de solo se ligam à redoma sensorial da percepção interna, pois o acrobata não 
tem nenhuma referência externa sobre o que está executando e a possibilidade de risco, portanto, é maior.

Outro exemplo é a conhecida perna-de-pau e a redoma sensorial de domínio da vertigem, algo que a princípio parece fácil mas não é, mesmo que a altura da perna-de-pau seja de poucos centímetros. O malabarismo, por sua vez, se relaciona com a redoma sensorial da visão periférica e da intuição manual; a cama elástica está referida à redoma sensorial de alteração da gravidade.

Por fim, Guilherme Veiga observou que o envolvimento com experiências sensoriais extra-cotidianas é tão impregnante que, nas entrevistas, houve vários relatos dos acrobatas descrevendo sonhos com suas atividades: sonhos de execuções perfeitas de atividades que ele já domina, sonhos de execução de atividades que ele ainda não sabe executar, sonhos com exercícios impossíveis de serem executados.

Guilherme Veiga conclui pela possibilidade de através da teoria das redomas sensoriais poder se estabelecer uma relação teórica entre ritual e espetáculo, cotidiano e extra-cotidiano e que, afinal, performance pode ser o nome dado a toda e qualquer transformação no campo sensorial ordinário, isto é, a construção de uma redoma sensorial extraordinária.

A percepção de quem resenha o livro é que o inusitado do empreendimento de Guilherme Veiga proporcionou uma contribuição inovadora aos estudos sobre performance, ainda tão mal entendidos apesar de consolidados pelo pioneirismo de Richard Schechner, Robert C. Corrigan, Victor Turner e outros.

Outro ponto é que, em determinada passagem, o autor afirma que a performance diz respeito a uma espécie de crise cultural e expressiva pela qual passa a sociedade contemporânea. Ele não se detém para desenvolver a idéia, mas o ponto chama a atenção para o 
fato de que depois das vanguardas do início do século XX seguiu-se uma sucessão infindável - e que não se pode considerar como bemsucedida -, de tentativas de recriar o novo, conseguir o impacto que criasse o sensorial extraordinário.

Experimentalismos os mais variados, todos impotentes diante de um mundo saturado de signos, símbolos, sinais, códigos, criados pela publicidade, pela tecnologia, pela simples necessidade de achar onde é o banheiro em um aeroporto, onde se pode virar o carro à direita ou atravessar a rua com segurança.

$\mathrm{Na}$ verdade, a indústria da cultura radicalizou a separação artista/espectador instaurada desde a Grécia Antiga e as vanguardas que tentam quebrar esta dicotomia esbarram no esgotamento da arte diante de tal tarefa. Exceções individuais e isoladas à parte, parece que o espetáculo triunfou sobre o ritual e a arte, incorporando até mesmo campos antes imunes, como as religiões. Há excesso de espetáculo em todos os campos (política, arte, cultura, religião), os rituais vazios, a falência da representação política - ela também transformada em espetáculo.

Não parece que o indivíduo contemporâneo esteja buscando o estranhamento, o olhar diferenciado. Pelo contrário, nada suscita seu espanto, sua suspeita, sua desconfiança. Sabe que é enganado e assim quer ser. $\mathrm{O}$ caso das festas de jovens, uso de drogas, esportes radicais são também busca de algo num ambiente saturado, onde não há mais o extraordinário. Talvez a busca de suprir a falta de coesão social pelo artifício. A dificuldade de encontrar redomas sensoriais alternativas.

Embora sem a devida ênfase, essas considerações finais de caráter mais melancólico e desesperançado não estão ausentes do livro de Guilherme Veiga. Mas, talvez, a aposta dele seja a de que a performance, tão cheia de possibilidades, possa vir a preencher esta falta. Não seria nada mau. 